\title{
Health and Roma People in Turkey
}

\author{
Perihan Elif Ekmekçi
}

TOBB University of Economics and Technology School of Medicine, Ankara, Turkey

Background: The research and published literature on Roma health in Turkey is much more limited than in other European countries. Among these, there are hardly any published literature focusing on the health status, health indicators and health behaviors.

Aims: The aim of this research is to describe the perceptions of health-related concepts and access and the use of health services and social determinants of the health of Roma people in Turkey.

Study Design: Descriptive qualitative survey.

Methods: The participants were chosen by random sampling. The semi-structured interview topic guide was developed from sources such as advice from the Romani community leaders, published evidence and personal experience from previous work with Roma communities. Non-directive open-ended questions allowed the exploration of their health status, how they conceptualize health and disease, their level of awareness on the impact of social determinants of health, on their health status and the access and use of health services. The data analysis was based on grounded theory. Analysis proceeded in four steps: 1. Reading and examining the transcripts separately using open coding, 2. Extracting the key words and codes from the transcripts and sorting them into categories, 3. Rereading the transcripts by using selective coding, and 4. Examining the categories derived from the open coding systematically and determining the concepts summarizing the material.

Results: The survey results are compatible with the existing literature on Roma health and reveal that 1) there is a tight link between the lack of social determinants of health and the poor health status of Roma people 2) socioeconomic factors and cultural norms of the ethnic minority are suspicious factors 3 ) comparative and systematic research is needed to illuminate the actual health gaps and causal factors for them.

Conclusion: The research proves that the need for comparative and systematic research in Turkey to determine the actual health status of Roma people and develop policies to combat the health disparities is profound.

Keywords: Roma people, health, ethnicity, public health, social determinants of health, qualitative methods
Roma People have been inhabitants of Anatolian lands and Europe since the Byzantine Empire (1). Today, Roma are the largest minority in Europe with an estimated population of seven to twelve million $(2,3)$. Although it is known that a significant number of the Roma population lives in Turkey, the exact number is not known due to a common attitude of reluctance to collect Roma-related data (4). Non-Governmental Organizations (NGOs) estimate the number of Roma people in Turkey to be around five hundred thousand to five million $(5,6)$.

The Roma population, being the largest ethnic minority in Europe, has attracted the attention of academics (7). Many researches are done regarding European Roma populations. However publications on the health status of Roma people are very limited in number (8). Besides most of them are on genetics or phylogenetics. A review of the published literature

Address for Correspondence: Dr. Perihan Elif Ekmekçi, TOBB University of Economics and Technology School of Medicine, Ankara, Turkey

Phone: +905322620350 e-mail:drpelifek@gmail.com

Received: 1 December $2015 \quad$ Accepted: 19 April $2016 \cdot$ DOI: 10.5152/balkanmedj.2016.151385

Available at www.balkanmedicaljournal.org 
between 1985 and 2003 show that of the 129 publications on Roma health issues, $50 \%$ of them have genetic characteristics of this unique minority (9). Furthermore publications on Roma populations come from three European countries: the Czech Republic, Slovakia, and Spain (10).

The survey made by Fundación Secretariado Gitano in collaboration with European Commission is one of the rare researches that supply comprehensive data regarding the health indicators of Roma population living in Bulgaria, Czech Republic, Greece, Portugal, Romania, Slovakia, and Spain. The results of the survey show a significant deficiency in health indicators of Roma when compared to the general population of these countries $(11,12)$. The United Nations Development Program (UNDP) human development report in 2003 reveals that the basic health indicators such as mother and infant mortality, low birth weight and life expectancy are significantly worse for the Roma population when compared to the non-Roma $(10,13)$. Literature reveal that in Bulgaria, Hungary and Romania the Roma People's access to social determinants of health is reported to be very limited when compared to the rest of the population. Masseria et al. (14) says that Roma people have significantly higher probability of reporting chronic diseases and feel threatened by illness because of unhygienic circumstances. Koupilova et al. (15) indicates that despite the poor health status of Roma people is often mentioned in literature, little concrete information exists about the current health problems of them.

The research and published literature on Roma health in Turkey is much more limited than the other European countries. Among these there are hardly any published literature focusing on health status, health indicators and health behaviors. This is a descriptive qualitative survey to estimate the current health status and perceptions of health-related concepts of Roma population living in Turkey.

\section{MATERIALS AND METHODS}

\section{Participants and setting}

The sampling frame is comprised of Roma living in Istanbul. Twenty semi-structured in-depth interviews were conducted. The participants were chosen by random sampling. Before the field survey, community leaders were contacted and they were informed about the survey to have their consent. Community leaders acted as facilitators to contact the participants. Ethical consent for the survey is obtained from TOBB University of Economics and Technology School of Medicine Ethics Committee.

\section{Interviews}

Data were collected by semi-structured in depth interviews in the participants' homes or at a place of their own choice.
The semi-structured interview topic guide was developed from sources such as advice from the Romani community leaders, published evidence and personal experience from previous work with Romani communities. The aim of the interviews was to let the participants to express their perceptions and situations in their own words. Non-directive open-ended questions allowed the exploration of their health status, how they conceptualize health and disease, their level of awareness on the impact of social determinants of health, on their health status and access to and use of health services. The interviews lasted for 1 to 2 hours. The conversations were recorded and transcribed verbatim.

\section{Data analysis}

The data analysis was based on grounded theory $(16,17)$. Analysis followed four steps: 1. Reading and examining the transcripts separately using open coding, 2. Extracting the key words and codes from the transcripts and sorting them into categories, 3 . Re-reading the transcripts by using selective coding, and 4. Examining the categories derived from the open coding systematically and determining the concepts summarizing the material.

\section{Respondent validation}

To verify the data analysis and test it for credibility, confidentiality and transferability, we introduced our findings to Romani people from other provinces of Turkey in three workshops. Apart from Romani people, social workers and representatives of non-governmental organizations were involved in these work-shops. No objections were raised about the confidentiality of the findings. The feedback from the work-shops suggested that the findings are meaningful and transferable.

\section{RESULTS}

\section{The perception of Roma about health and disease concepts}

All participants choose to describe health as a collective well-being rather than an individualistic wellness $(18,19)$. When the participants were asked about their health they referred to their families, children and other beloved ones. They indicate that they feel healthy if their family is healthy, safe and secure. Participants link well-being and health concepts with being peaceful and happy, physically active and free of chronic diseases, and having sustainable and regular income.

Respondents consider being physically active as a sign of being healthy. Thus, intellectual activities are not regarded as valuable and normal, as physical activities are (20). Consider- 
TABLE 1. The perception of Roma people about health and disease

- Health is a collective well-being rather than an individualistic state

The perception about health

- Being physically active is a sign of being healthy

- Disease is a permanent state of being useless/being a burden for the community

The perception about disease

- Denial of the symptoms and refusing healthcare for chronic diseases is common

TABLE 2. Main challenges of Roma health

\begin{tabular}{ll}
\hline & Poor housing and environmental \\
& pollution \\
Social determinants of health & Occupational health and safety \\
& - Lack of social activities \\
& Lack of education and \\
& unemployment \\
\hline & Financial constrains \\
- Discrimination and stigmatization & Skepticism and Insecurity \\
Access and use of health services & Health illiteracy and cultural norms \\
\hline
\end{tabular}

ing the daily life and living conditions of Roma, this perception seems rational. Roma People mostly earn their living by choosing work that requires muscle power. Thus physically powerful and active individuals are considered healthy.

In parallel with this view, disease is conceptualized as a permanent state of being useless as a human being. The participants think that a diseased person is someone who cannot work and earn money; thus, that person is of no use for the community life, but is a burden instead. This negative perception leads them to deny their diseases, and to reject asking for health services until their disease becomes unbearable. One of the participants told that her father, who had serious renal failure, resisted hospitalization and tried to keep up with his daily routine until his body collapsed. She thinks that the reason why her father behaved like this was to avoid ruining his reputation of being brave and strong. She quoted from her father; "If I go to the hospital everybody will say; colossal Murat is a useless wretch now. I would rather die than hear that."

\section{Social determinants of health \\ Poor housing and environmental pollution}

Participants think poor housing has a devastating effect on their health status. In describing the threats to their health, par- ticipants, referred directly to small, old and ruinous houses. Participants indicate that the houses are mostly slums and more than one family lives in each house. New rooms are built as attachments to the houses for newly married couples. All of the family members use the available place for living, eating, cooking, sleeping and studying. Only a small number of houses have a separate and proper kitchen and bathroom. Most of the houses have electricity and tap water, but participants say that dwellers find it hard to pay for these facilities.

Respondents indicate that environmental pollution is a risk for their health. They state that due to financial constraints they experience difficulties sparing money for heating in the winter. Thus, they burn garbage or cheap bad quality charcoals in their stoves to heat the houses, which reveal a thick fuliginous air. We observed that it is very hard to breathe when the stoves are lit in the early evening hours.

The garbage hummocks are frequent in Roma neighborhood. Participants protest this, saying their children are playing in the garbage all through the day. They consider this situation a threat for their children's health. Another factor regarding environmental pollution is the poor sewage system. Although a sewage system is constructed in most of the Roma neighborhoods, participants say it gets choked frequently, leaving the district dirty and flooded. Roma women are plaintive about the situation and they consider it the reason for diarrhea epidemics among children.

\section{Occupational health and safety}

Roma people earn their lives by selling flowers along road side, collecting garbage from the containers, begging money or cleaning houses and offices. Perceived disadvantages of these occupations are, close contact with filthiness, being prone to accidents, abuse and inhaling toxic materials. Participants think the high incidence of chronic respiratory diseases and communicable diseases arise from their unsuitable occupational conditions. One of the male participants was earning his life by collecting garbage. He showed his hands and asked: "Look at my hands. They are as black as soot because they are in garbage all day. When I come home I wash my hands with bleache but it is of no use. How can I be healthy when I am blended to filth all over?"

\section{Lack of social activities}

Some participants consider lack of social and cultural activities as threats for their social well-being. A female participant complained about the lack of venues where they can pursue their hobbies, read books or socialize with peers.

\section{Lack of education and unemployment}

Participants also touched on the negative impact of being illiterate or lacking diplomas form elementary school. Many 
job opportunities require elementary school diplomas. This creates a big challenge for Roma People. Most of the young adults, who have the responsibility to sustain the family, don't have an official diploma. Therefore they are urged to get daily jobs like garbage collecting or selling flowers. Thus they don't have sustainable regular income and any social security or health insurance. This creates a positive feed-back to increase poverty and social exclusion and adds on the disadvantaged status of Roma.

\section{Access and use of health services}

The most remarkable factors holding the Roma People back from access to health services are financial constraints, the feeling of insecurity, skeptical attitude towards public institutions and ignorance about the procedures of the hospital.

\section{Financial constrains}

Participants declared that financial constrains constitute big barriers to access health services. The requirement of out of pocket payments, the co-payment for the drugs and travel expenditure to and from the hospital are considered to be catastrophic by the participants. Some participants said they have to choose between feeding their family for the day and going to the hospital.

\section{Skepticism and insecurity}

Participants indicated that they share a skeptical attitude towards the State institutions such as hospitals and they don't feel safe there. In addition to skepticism, they revealed another fact that prevents them from going to hospital, which is their ignorance about the procedures they have to follow. Therefore, participants said that, some of the Roma prefer to apply to local family physicians, a safe, cheap and well known place for them instead of big, chaotic hospitals. However, the family physician offices are not well-equipped to cure and manage complex health problems.

When applying to hospital is unavoidable, a group of Roma People accompanies the diseased. This group includes a mediator for the official procedures and a relative or a friend to assist during physical examination or laboratory tests.

\section{Discrimination and stigmatization}

In describing their experiences with health personnel, the participants referred to discrimination and stigmatization. One of the participants said "They understand that we are Roma form the way we look. They told my old mother to go all the way back the line when they saw her long colorful skirt and head cover." Participants indicated that they face this manner mainly from nurses and assistant health personnel. There was a consensus about the feeling they get from some nurses and healthcare staff; Roma are an undesired group of patients compared to non-Roma patients.

\section{Health illiteracy and cultural norms}

Roma People have a low level of health literacy. One of the participants said that his father's leg was amputated due to diabetic foot and his brother had suffered from the same health problem since he was a child. When he was asked if he'd had his blood glucose checked, he looked startled, and said that he does not understand why he needs to. Another participant said she has to cover the baby with blankets when the baby has a high fever. She thinks she has to keep her baby warmer as the baby's temperature rises.

The access to health services during pregnancy has particular characteristics (21). Participants referred to the cultural norm which prevents them from making frequent doctor visits. They indicated that the elderly women of the family are mostly in charge of caring for the pregnant and they do not approve of young pregnant women visiting the doctors often. The general view of participants about pregnancy is that it is a normal process proceeding according to the rules of nature and does not require artificial outsider involvements such as doctor visits.

A similar manner is declared about vaccination programs. Objections against vaccination were the myths about the harmful effects of vaccines, the skepticism towards the medical implementations of the outsiders and the ignorance of the parents.

\section{DISCUSSION}

This survey is limited by interviewing members of a particular group of an ethnic minority. Therefore the emergent themes from the data analysis of the interviews would not necessarily be applicable to all Roma population of Turkey. However, the prominent themes were discussed with Roma people from various provinces of Turkey, social workers and representatives of NGOs and they ensured the existence, meaningfulness and transferability of them. Therefore, the results of the survey are likely to represent the perceptions and actual health status of Roma people in general.

Health was directly attributed to collective well-being and peace and conformity of the household instead of an individualistic state. This is congruent with the literature on Roma culture regarding dominance of collective well-being and sacrificing the individual for the sake of the welfare and survival of the community $(20,22)$. Being physically active was referred to as an indicator of well-being and being free of diseases. Common occupations of Roma people depend on muscle 
power. The ability to perform physical activity is considered to be a sign of being healthy, whereas being diseased is conceptualized as a disability which affects daily physical activity. In this context, a diseased person is perceived as a disabled individual who cannot work and add to the well-being of the household. This apprehension may be a contributing factor for the relatively low number of hospital admissions and of Roma community with respect to the general society (23).

There was a prominent link between health and negative impacts of social determinants of health. Poor housing, environmental pollution, unemployment, lack of occupational safety, and illiteracy are indicated as the main risk factors for health. In this context, financial constrains are both elementary causal factor for the negative social determinants and a barrier for access to health services. Health illiteracy and ignorance were remarkable factors of the social determinants of health. They are considered both as a causal factor and an outcome of this vicious circle of deprivation. Akkan et al. (24) have similar findings to our research. They reported that a lack of social determinants of health and poor social inclusion of Roma people are among the major factors that affect Roma peoples' health negatively. The field survey by Ekmekci (25) that was conducted in six provinces with dens Roma population reveal the importance of social and economic factors.

These results are in agreement with Marmot's report in which he emphasized the huge impact of social determinants of health on the actual health status of communities (26). Furthermore the lack of social determinants of health together with unemployment and poverty indicate low socioeconomic status. Thus they may be discussed in the context of fundamental causal theory $(27,28)$. Both feelings of insecurity and skepticism towards state institutions are mirrored among the major themes arising from this survey. The dominance of collective pattern of attendance to the health institutions arise as a result of this perception. The literature on the health behaviors of Roma people supports this finding (18). Roma people are recognized to appear in groups of three or more by the health professionals (29). However surveys on other disadvantaged groups such as LGBT or ethnic minorities, which are likely to be subject to discrimination or stigmatization, need to be pursued to distinguish whether this attitude arises from a unique cultural norm or if it is a common defensive attitude of vulnerable groups towards the dominant culture of society.

Cultural codes such as the hierarchical order of the Roma community expose itself regarding health behaviors during pregnancy. The literature on the Roma culture confirm the ruling power of elderly women over young ones $(18,20,22)$. The findings about health behaviors can be interpreted in this context. Furthermore conceptualizing pregnancy as a normal process which proceeds according to the rules of nature which does not require artificial outsider involvements, may be considered an indicator of how the cultural perceptions may affect health behaviors (30).

Financial constraints and lack of health insurance are among the main barriers of access to health services. This result is compatible with limited research on Roma peoples' access to health services in Turkey. Berberoğlu et al. found that economic deprivation and lack of insurance were major factors behind Roma people in the Trakya region avoiding accessing health services (31).

The survey results are compatible with the existing literature on Roma health and reveal that: 1 . There is a tight link between the lack of social determinants of health and the poor health status of Roma people $(5,9,32), 2$. Socioeconomic factors and cultural norms of the ethnic minority are suspicious factors $(14,23,33)$, and 3. Comparative and systematic research is needed to illuminate the actual health gaps and causal factors for them (33).

Ethics Committee Approval: Ethics committee approval was received for this study from the ethics committee of TOBB University of Economics and Technology School of Medicine.

Informed Consent: Written informed consent was obtained from participants who participated in this study.

Peer-review: Externally peer-reviewed.

Conflict of Interest: No conflict of interest was declared by the authors.

Financial Disclosure: The authors declared that this study has received no financial support.

\section{REFERENCES}

1. Gresham D, Morar B, Underhill PA, Passarino G, Lin AA, Wise $\mathrm{C}$, et al. Origins and Divergence of the Roma (Gypsies) $\mathrm{Am} J$ Hum Genet 2001;69:1314-31. [Crossref]

2. Brearley M. The Persecution of Gypsies in Europe. American Behavioral Scientist 2001;45:588-99. [Crossref]

3. Tanner, A. 'The Roma of Eastern Europe: Still searching for inclusion. Migration Policy Institute. 2005 Available online at http://www.migrationpolicy.org/article/roma-eastern-europestill-searching-inclusion

4. Walsh CA, Este D, Krieg B. The Enculturation Experience of Roma Refugees: A Canadian Perspective. British Journal of Social Work 2008;38:900-17. [Crossref]

5. Hajioff $\mathrm{S}, \mathrm{McKee} \mathrm{M}$. The health of the Roma people: a review of the published literature. J Epidemiol Community Health 2000;54:864-9. [Crossref] 
6. Arus E. Buçuk. Yönetmen: H. Haluk Arus \& Elmas Arus, 2007; İstanbul, Türkiye

7. Stewart M. Roma and Gypsy "Ethnicity" as a Subject of Anthropological Inquiry. Annu Rev Anthropol 2013;42:415-32. [Crossref]

8. Rachel B, Blackburn CM, Spencer NJ, Rechel B. Access to health care for Roma children in Central and Eastern Europe: findings from a qualitative study in Bulgaria. Int J Equity Health 2009;8:24. [Crossref]

9. Zeman CL, Depken DE, Senchina DS. Roma health issues: a review of the literature and discussion. Ethn Health 2003;8:22349. [Crossref]

10. Sepkowitz KA Health of the world's Roma population. Lancet 2006;367,9524:1707-8. [Crossref]

11. Fundación Secretariado Gitano. Health and the Roma Community, Analysis of action proposals. Madrid: Directorate-General for Public Health Ministry of Health and Consumer Affairs Area of Health 2004.

12. Fundación Secretariado Gitano. Health and the Roma Community, Analysis of the situation in Europe. Bulgaria, Czech Republic, Greece, Portugal, Romania, Slovakia, Spain. Madrid: Cuadernos Técnicos No 972009.

13. United Nations Development Program. Avoiding the dependency trap: the Roma human development report. Roma Human Development Report, 2003.

14. Masseria C, Mladoksy P, Hernandez-Quevedo C. The socioeconomic determinants of the health status of Roma in comparison with non-Roma in Bulgaria, Hungary and Romania. Eur J Public Health 2009;20:549-54. [Crossref]

15. Koupilová I, Epstein H, Holcík J, Hajioff S, McKee M. Health needs of the Roma population in the Czech and Slovak Republics. Soc Sci Med 2001;53:1191-204. [Crossref]

16. Strauss A, Corbin J. Basics of qualitative research. Newbury Park. Sage Publications, 1990.

17. Maxwell AJ. Qualitative Research and Desing An İnteractive Approach. 1st Ed. London: Sage Pub 2013;114-8.

18. Lehti A, Mattson B. Health, Atttude to care and pattern of attendence mong gypsy women- a general practice perspective. Fam Pract 2001;18:445-8. [Crossref]

19. Ekmekci A Study on Right to Health and Roma People in the Scope of Medical Ethics. Ankara 2014. Avaliable at https://tez. yok.gov.tr/UlusalTezMerkezi/
20. Fonseca I. Beni ayakta Gömün (Bury me standing: the gypsies and their journey.) 1. Edition. İstanbul: 2002. Ayrıntı Press

21. Reid B, Taylor J. A feminist exploration of Traveller women's experiences of maternity care in the Republic of Ireland. Midwifery 2007;23:24-59. [Crossref]

22. Weyrauch Gypsy law: Romani legal traditions and culture. Berkley and Los Angeles: 2003 Unv. of California Press.

23. Kolarcik P, Geckova AM, Orosova O, van Dijk JP, Reijneveld SA. Predictors of health-endangering behaviour among Roma and non-Roma adolescents in Slovakia by gender. $J$ Epidemiol Community Health 2010;64:1043-8. [Crossref]

24. Akkan BE, Deniz MB, Ertan M. Sosyal dıșanmanın Roman Halleri. Punto Baskı çözümleri. İstanbul 2011.

25. Ekmekci PE. Sağlık ve Romanlar; Türkiye'de yaşayan Romanlara yönelik niteliksel bir araştırma. Sürekli Tıp Eğitimi Dergisi 2015;24:142-9.

26. Marmot, M. Fair Society Healthy Lives: The Marmot Review: Strategic Review of Health Inequalities in England 1st Ed. post2010. ISBN 9780956487001

27. Link BG, Phelan J. Social conditions as fundamantal causes of disease. J Health Soc Behav 1995;35:80-94. [Crossref]

28. Phelan JC, Link BG, Diez-Roux A, Kawachi I, Levin B. "Fundamental causes" of social inequalities in mortality: A test of the theory. J Health Soc Behav 2004;45:265-85. [Crossref]

29. SutherlandA. Gypsies and health care. West J Med 1992:157;27680.

30. Cleemput PV, Parry G, Thomas K, Peters J, Cooper C. Healthrelated beliefs and experiences of Gypsies and Travellers: a qualitative study. J Epidemiol Community Health 2007;61:20510. [Crossref]

31. Berberoğlu U, Eskiocak M, Ekuklu G, Saltık A. Edirne ili Muradiye sağlı ocağ 1 bölgesinde Romanlar ve öbürlerinin ilk basamak sağlık hizmeti kullanımı. Toplum ve Hekim 2001;6:470-5.

32. Mladovsky P. To what extent are Roma disadvantaged in terms of health and access to health care? What policies have been introduced to foster health and social inclusion? Research Note for the European Commission, DG Employment and Social Affairs 2007.

33. Földes EM, Covaci A. Reseach on Roma health and access to healthcare: state of the art and future challenges. Int J Public Health 2012;57:37-9. [Crossref] 